\title{
Ternary organic solar cells doped methoxyphenyl indenopyrazoloquinoline derivatives
}

\author{
Gabriela Lewińska ${ }^{1}$ (D) $\mathrm{Krzysztof} \mathrm{S.} \mathrm{Danel}^{2} \cdot$ Izabela Łukaszewska $^{3} \cdot$ Grzegorz Lewiński $^{4} \cdot$ Wiktor Niemiec $^{5}$. \\ Jerzy Sanetra ${ }^{1}$
}

Received: 8 June 2018 / Accepted: 16 August 2018 / Published online: 23 August 2018

(c) The Author(s) 2018

\begin{abstract}
This paper discusses the results for heterojunction solar cells based on three components (with fullerene acceptor), which are based on the pyrazoloquinoline derivative. Photovoltaic devices based on ternary systems are presented along with a model optimization for such mixtures. The device bulk-heterojunction type cells represent architecture ITO/PEDOT:PSS/ organic active layer/aluminum in various configurations of the active layers. The authors have analyzed the current-voltage characteristics of photovoltaic cells and determined the parameters.
\end{abstract}

\section{Introduction}

The constant increase in electric demand, resulting from advancements in technology and a rapid growth in population, has contributed to higher demands for energy. With the ever-growing importance of protecting the natural environment, renewable energy sources, including photovoltaic cells, have become increasingly popular [1,2]. So far, three generations of photovoltaic cells have been developed: silicon [3], so-called semiconductor thin-layer cells $[4,5]$ and the third generation, consisting of dyes [6, 7], organic cells $[8,9]$, polymers and perovskites $[10,11]$ cells.

One of the current research trends in organic solar cells is to use a ternary mixture as active layers in bulk heterojunction solar cells [12]. A typical active layer is produced by blending conjugated polymers (donor) with high electron

Gabriela Lewińska

glewinska@pk.edu.pl

1 Institute of Physics, Cracow University of Technology, ul. Podchorążych 1, 30-084 Kraków, Poland

2 Institute of Chemistry, Agricultural University, ul. Balicka 122, 31-149 Kraków, Poland

3 Faculty of Chemical Engineering and Technology, Cracow University of Technology, Warszawska 24, 31-155 Kraków, Poland

4 Ocado Poland, Rakowicka 7, 31-511 Kraków, Poland

5 Faculty of Materials Science and Ceramics, AGH University of Science and Technology, al. Mickiewicza 30, 30-962 Kraków, Poland affinity molecules (acceptor), like fullerene derivatives. In principle we can consider two types of ternary solar cellsDonor 1: Donor 2: Acceptor and Donor: Acceptor 1: Acceptor $2[13,14]$. The publication concerns the active layer with two donors and one acceptor.

The motivation behind creating ternary systems is, above all, a relatively low, narrow spectral overlap of organic polymer absorption. Nanoparticles $[15,16]$, polymers $[17,18]$ and small molecule compounds [19] are developed as additives. The studied compounds are suitable potential candidates for optoelectronic application in general and particularly for ternary solar cells [20-23].

\section{Compounds}

The mixture is comprised of the following: [phenyl-C71-butyric acid methyl ester (PCBM)] as the acceptor; poly(3-hexylthiophene-2,5-diyl) (P3HT), provided by Sigma-Aldrich, as Donor1 (Fig. 1); methoxyphenyl indenopyrazoloquinoline derivatives (synthesized) have been applied as additives for Donor 2. They can be considered as two-dimensionally extended, polycyclic heteroaromatic molecules, called nanographenes, which can play a key role as functional chromophores and organic semiconductors [24].

The compounds $1 \mathrm{a}-\mathrm{c}$ were synthesized in a three-step procedure. Firstly, commercially available $\beta$-ketoester was heated with methylhydrazine in boiling ethanol. Next, the obtained pyrazolone, $o$-bromobenzaldehyde, and aromatic amines were heated to reflux in ethylene glycol. Lastly, 
Fig. 1 Molecular structures of a-c methoxyphenyl indenopyrazoloquinoline derivatives, $\mathbf{d}$ $\mathrm{P} 3 \mathrm{HT}$ and e PCBM
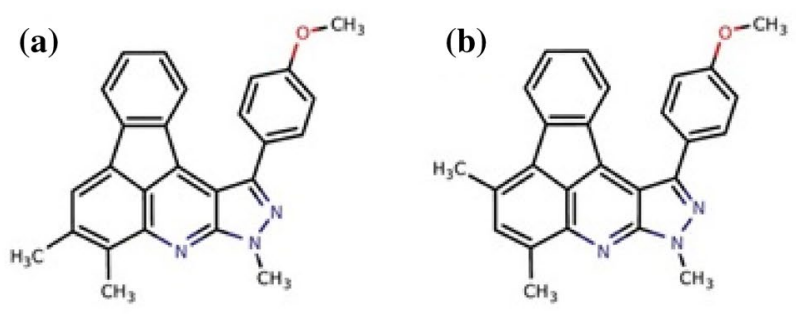<smiles>COc1ccc(-c2nn(C)c3nc4cc(C)c(C)c5c4c(c23)-c2ccccc2-5)cc1</smiles>

(d)

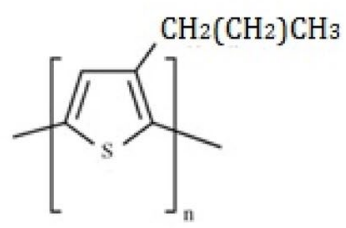

(e)

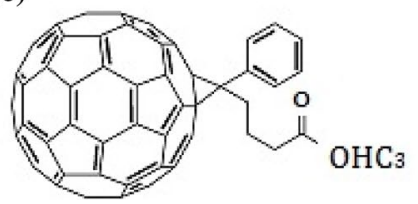

halo-pyrazolo[3,4-b]quinolines 1a-c, the right precursors by means of palladium coupling reactions were converted into indenopyrazoloquinoline (azafluoranthene) derivatives [25] (Fig. 2).

The methoxyphenyl indenopyrazoloquinoline derivatives have been previously investigated and accepted as promising compounds for organic light emitting diodes [26]. Photovoltaic substances require certain properties to be used in cells. The solar cells material properties are complementary to those required in diodes. Methoxyphenyl indenopyrazoloquinolines are characterized by a broad absorption spectrum, luminescence, as well as thermal and photochemical stability. The compounds designated as MPTM-IPQ1, MPTM-IPQ2, MPTM-IPQ3 have almost identical broad absorption spectrums of $250-450 \mathrm{~nm}$, with two maxima and a luminescence spectrum maximum of $550 \mathrm{~nm}$. HOMO LUMO levels were determined by cyclic voltammetry as follows: MPTM-IPQ1: HOMO level - 5.91 eV LUMO level - 3.18 eV; MPTM-IPQ2 HOMO level - 5.91 eV LUMO level - 3.21 eV, MPTM-IPQ3: HOMO level - 5.88 eV LUMO level - 3.17 eV.

The primary motivation for adding another component was to widen the absorption spectrum. P3HT has a maximum at about $450 \mathrm{~nm}$, and it was desired to include the UV part of the solar spectrum. As presented in Fig. 3, when two donors are used, a wide band from $250 \mathrm{~nm}$ to $550 \mathrm{~nm}$ is covered.

Other reasons to add MPTM-IPQ substances are the well-coordinated HOMO and LUMO levels of the three involved compounds. The triple system, due to the proximity of the energy levels, as well as the possibility of cascading the charge transport [27], seems promising. Due to the low ability to charge transport, well transportable fullerene compounds (in our case PCBM, with the carrier mobility of $0.21 \mathrm{~cm}^{2} / \mathrm{Vs}$ ) are required. The mixing of substances has been shown to be an attractive way for controlling the morphology of the active layers.
Fig. 2 A chemical sequence to prepare methoxyphenyl indenopyrazoloquinoline derivatives

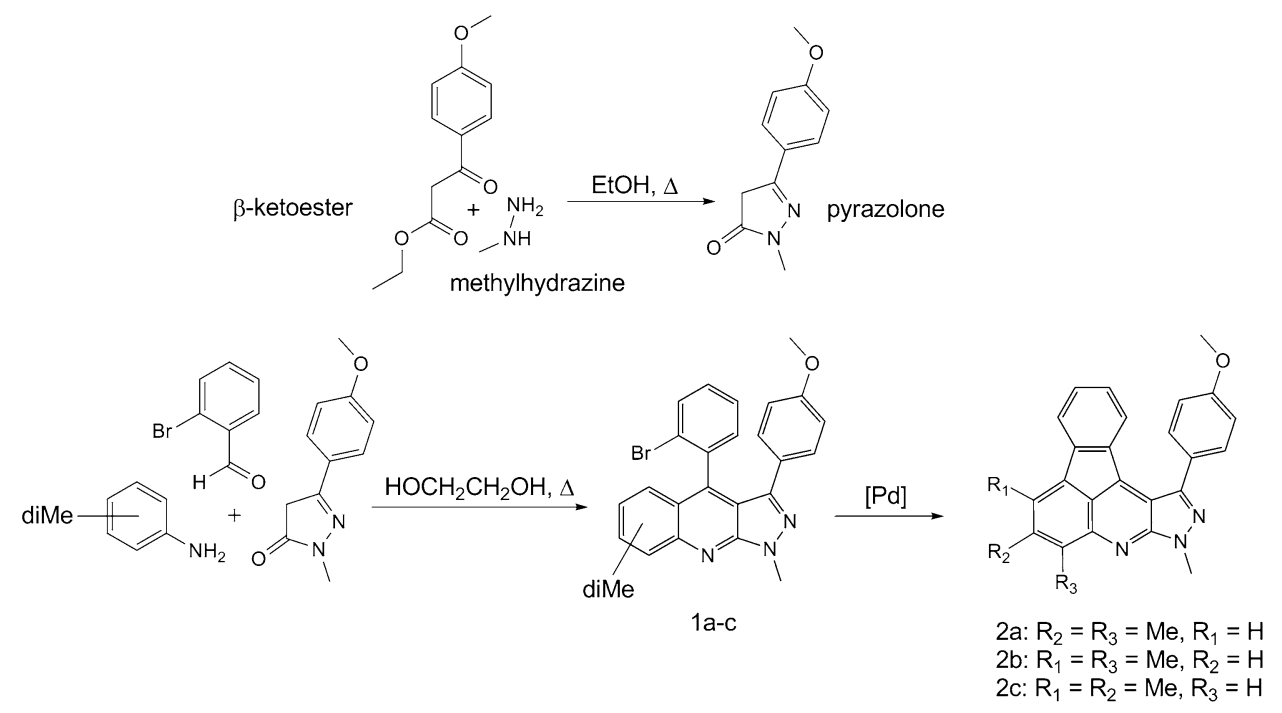




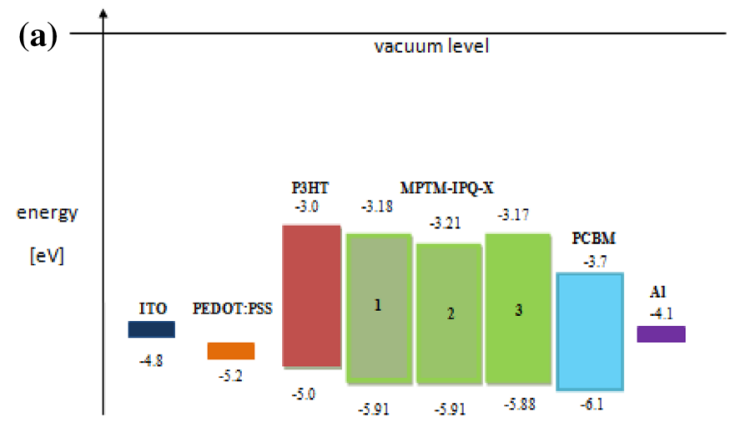

(b)

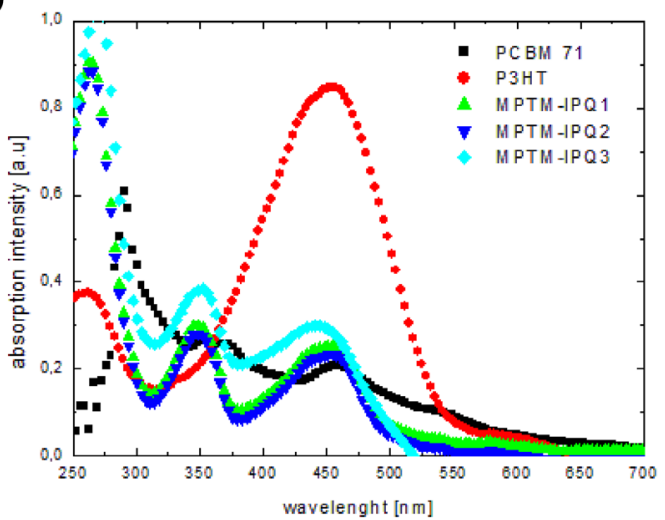

Fig. 3 a HOMO LUMO diagrams and b absorption spectra of PCBM, P3HT, MPTM-IPQ1, MPTM-IPQ2, MPTM-IPQ3

\section{Calculations}

The first problem encountered was to find an appropriate Donor 1: Donor 2 weight ratio. The optimization of the weight ratio of the two donors according to the algorithm has been precisely described in Felekidis [28].

The respective absorption lengths for donors were combined, which included weight fractions $\mathrm{f}_{\mathrm{D} 1}, \mathrm{f}_{\mathrm{D} 2}$, attenuation lengths $\mathrm{L}_{\mathrm{D} 10}, \mathrm{~L}_{\mathrm{D} 20}$ (obtained from ellipsometry measurements) and absorption profiles, which included absorption spectra parameters, absorption maximum $\lambda_{\max 1,2}$, and full width at half maximum (FWHM), $\mathrm{W}_{\mathrm{D} 1,2}$

$L_{D 1}(\lambda)=\frac{L_{D 10}}{G_{D 1}(\lambda) \cdot f_{D 1}}$

$L_{D 2}(\lambda)=\frac{L_{D 20}}{G_{D 1}(\lambda) \cdot\left(1-f_{D 1}\right)}$

$G_{D 1,2}(\lambda)=\exp \left(-4 \log 2\left(\frac{\lambda-\lambda_{\max 1,2}}{W_{D 1,2}}\right)\right)$

The combination of results as effective absorption length:

$\frac{1}{L_{e f f}(\lambda)}=\frac{1}{L_{D 1}(\lambda)}+\frac{1}{L_{D 2}(\lambda)}$

based on this and given the thickness of the device $\mathrm{L}_{\text {div }}$ we obtain device absorption:

$\mathrm{A}(\lambda)=1-\exp \left(-\frac{\mathrm{L}_{\mathrm{div}}}{\mathrm{L}_{\mathrm{eff}}(\lambda)}\right)$

Assuming, [35] the internal quantum efficiency at $I Q E=0.85$, and including the AM 1.5 as Standard Spectrum, the normalized absorption was defined as:
$\dot{\eta}=\frac{1}{\mathrm{~L}_{\mathrm{div}}} \int \frac{A M 1.5(\lambda) \cdot I Q E \cdot A(\lambda)}{\mathrm{E}_{\text {photon }}} \mathrm{d} \lambda$

The normalized absorption was calculated for different concentrations and thicknesses from $70 \mathrm{~nm}$ to $140 \mathrm{~nm}$ for P3HT and MPTM-IPQ1, MPTM-IPQ2, MPTM-IPQ3 combinations. Due to the fixed density of the mixtures, at different application rates, the selected configurations are possible to be obtained experimentally. Results are presented in Fig. 4.

Figure 4 lead us to two conclusions- the methoxyphenyl indenopyrazoloquinoline derivatives do not improve performance and cells should be prepared using the thinnest layers as possible. Furthermore, differences between sequels are minimal. It should be noted that this model only considers the optical properties of the compounds.

\section{Experiment}

\subsection{Heterojunction solar cells}

Bulk heterojunction ternary photovoltaic cells based on ITO/PEDOT: PSS/active layer/Al architecture have been prepared. The PEDOT: PSS [(3,4-ethylenedioxythiophene) polystyrene sulfonate] layer (about $60 \mathrm{~nm}$ in thickness) and the active layer were spin-coated on a cleaned ITO/ glass substrate in an argon atmosphere and then heated in a vacuum. The aluminum contact was evaporated. The Donors-Acceptors weight ratio used in these cells was 1:1. The current-voltage characteristics were studied and the cell parameters (short current density $\mathrm{I}_{\mathrm{sc}}$, open circuit voltage $V_{o c}$, fill factor FF, efficiency) were calculated based on 

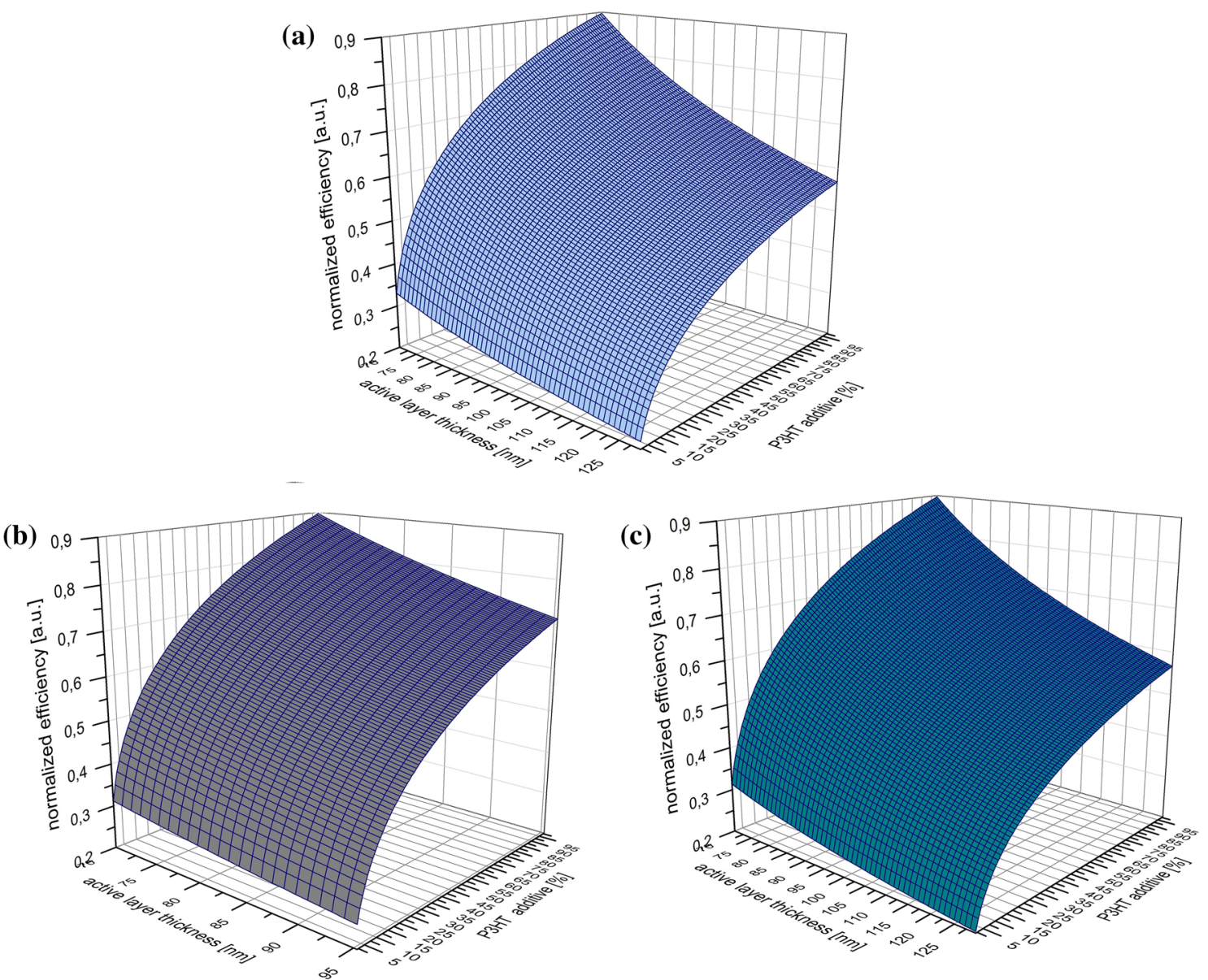

Fig. 4 Calculated normalized efficiency versus active layer thickness versus Donor 1 concentration for a MPTM-IPQ1, b MPTM-IPQ2, c MPTM-IPQ3

Table 1 Parameters describing the photovoltaic devices

\begin{tabular}{lllll}
\hline Sample & $\mathrm{I}_{\mathrm{SC}}\left[\mu \mathrm{A} / \mathrm{cm}^{2}\right]$ & \multicolumn{1}{l}{$\mathrm{U}_{\mathrm{oc}}[\mathrm{V}]$} & $\mathrm{FF}$ & Efficiency [\%] \\
\hline P3HT:PCBM & $864.5 \pm 0.58$ & $0.386 \pm 0.029$ & $0.245 \pm 0.025$ & $3.71 \pm 0.39$ \\
MPTM-IPQ1 + P3HT: PCBM & $446.1 \pm 0.58$ & $0.390 \pm 0.029$ & $0.348 \pm 0.034$ & $2.32 \pm 0.28$ \\
MPTM-IPQ2+P3HT: PCBM 5\% & $158.3 \pm 0.58$ & $0.490 \pm 0.029$ & $0.958 \pm 0.026$ & $3.70 \pm 0.43$ \\
MPTM-IPQ3 + P3HT: PCBM 5\% & $671.4 \pm 0.58$ & $0.430 \pm 0.029$ & $0.26 \pm 0.024$ & $2.92 \pm 0.27$ \\
\hline
\end{tabular}

It is possible to consider donors mixture excitation. The HOMO/LUMO energy offset should be equal to or larger than the binding energy of singlet and triplet excitons [29]. The best performance of the MPTM-IPQ2 compound can also be justified by the maximum LUMO energy offset noted by this substance. LUMO energy offsets achieved for compounds a MPTM-IPQ1, MPTM-IPQ2 MPTM-IPQ3 are $0.18 \mathrm{eV}, 0.21 \mathrm{eV}, 0.17 \mathrm{eV}$, respectively. This energy levels system determine the optimal photocurrent of dissociation most of the singlet excitons, which need at least $0.07 \mathrm{eV}$ energy and correspond, as part of a donor-acceptor mixture, with charge transfer complexes forming. 


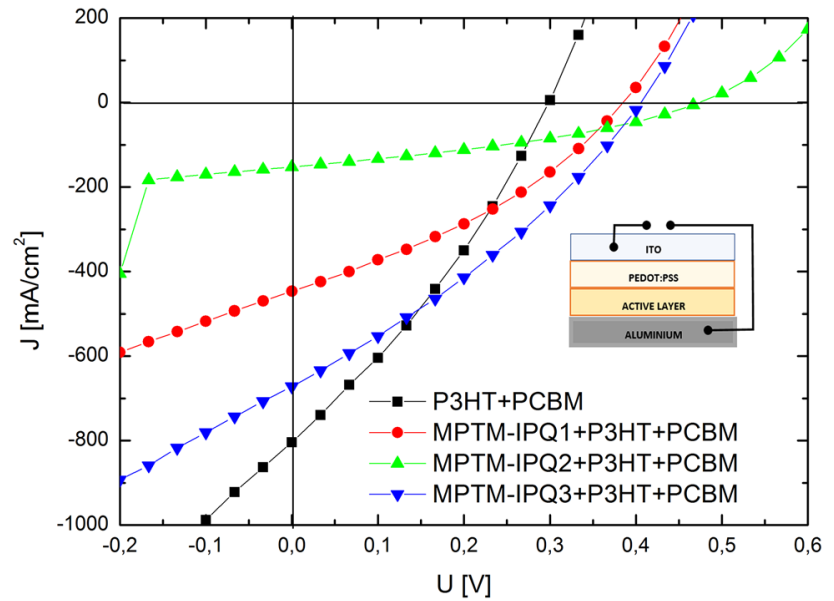

Fig. 5 Current-voltage characteristics

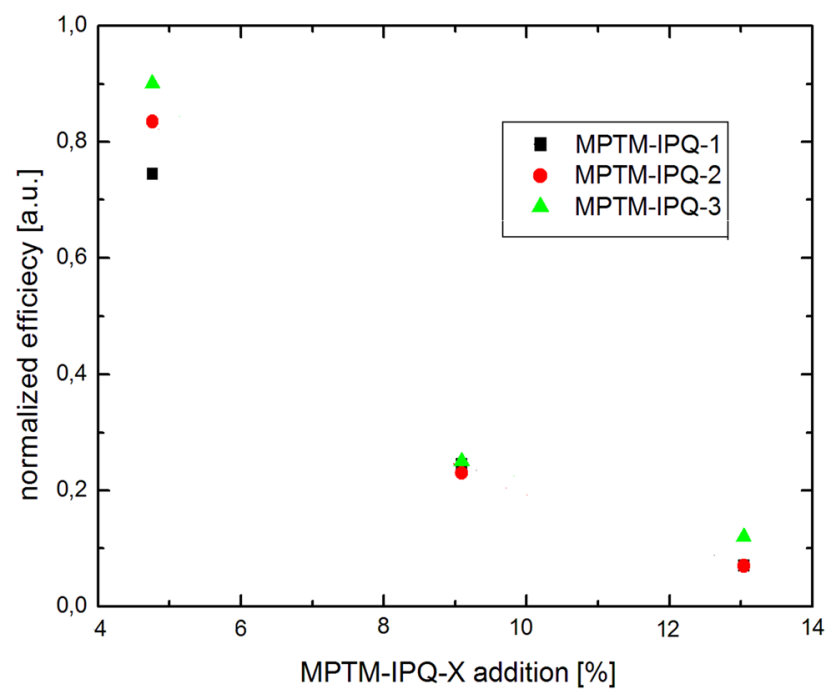

Fig. 6 Normalized efficiency versus MPTM-IPQ concentration

Several series of devices were made for various concentrations and thicknesses. The results are shown in the graphs for comparison (Figs. 6, 7). The devices were submitted for standardized absorption (normalized to P3HT: PCBM efficiency). The decrease in efficiency caused by an increase in the concentration of the second donor is compatible with the predictions of the theoretical model. However, reducing thickness has no positive effect on solar cell performance.

On the other hand, the introduction of the second donor has positively influenced the open circuit voltage $V_{\text {oc }}$ (connected with crystallinity, the random copolymer effect surface energy, which are correlated with the properties of the polymers). For each concentration and thickness, we have seen an improvement over P3HT: PCBM device. Higher

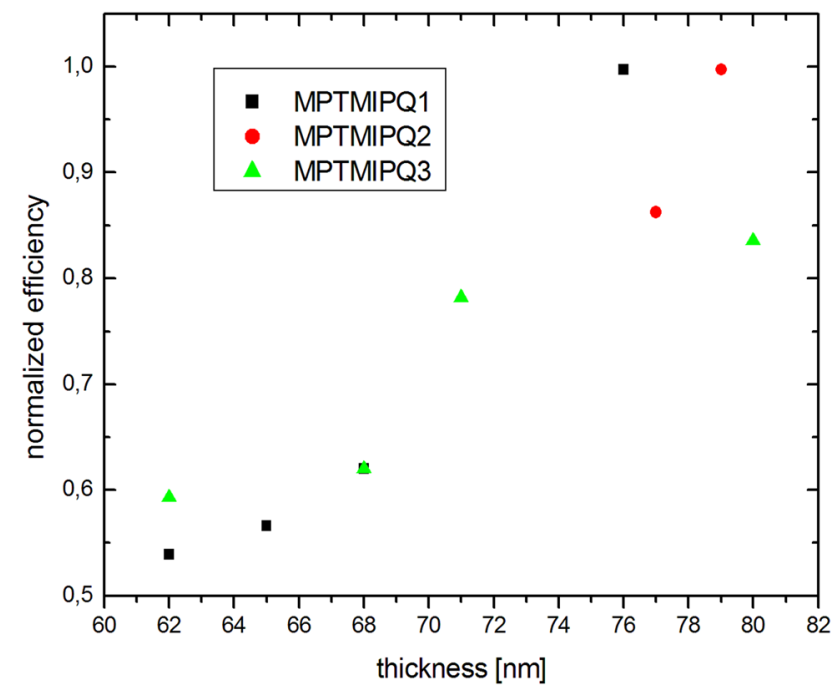

Fig. 7 Normalized efficiency versus active layer thickness

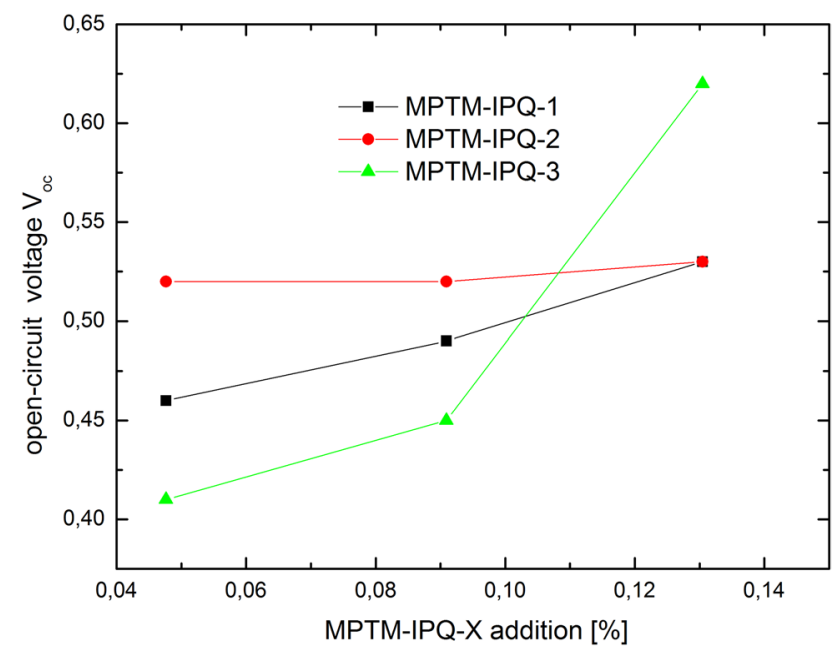

Fig. 8 Open circuit voltage Voc versus MPTM-IPQ concentration

open circuit voltage was observed by Wang et al. [30] (Fig. 8).

The results show that this kind of active layer requires simultaneously improving the short circuit current and open circuit voltage (e.g., by nanoparticles dopping).

The possibility of using the substance as an acceptor should also be considered. Based on the MPTM-IPQ absorption spectra, it can be assumed that the compounds can act as an acceptor in P3HT: MPTM-IPQ systems. Bulk heterojunction solar cells architecture ITO/PEDOT: PSS/ P3HT + MPTM-IPQ/Aluminum was performed. For all three substances the efficiency of the cell was under $1 \%$. 


\subsection{Surface measurements}

The spectroscopic ellipsometry [31], (Woollam Spectroscopic Ellipsometry M-2000) method has been performed. This was done to determine the refractive index and extinction coefficient of MPTM-IPQ, as well as thickness and roughness of layers in heterojunction solar cells.

To obtain coefficients for MPTM-IPQ compounds measurements were made for angles $\left(60^{\circ}, 65^{\circ}, 70^{\circ}, 75^{\circ}\right)$ and wavelength range $300-1800 \mathrm{~nm}$ on a corning glass substrate. The ellipsometry spectrum and parameters for PCBM and P3HT are known from Campoy-Quiles et al. [32]. Tauc-Lorentz model [33, 34] was matched to ellipsometric parameters: $\Psi$-amplitude ratio and $\Delta-$ phase difference between p- and s- polarized light waves (p-polarized light has an electric field polarized parallel to the plane of incidence, while s-polarized light is perpendicular to this plane). The modeling process was done using software CompleteEASETM. The dispersion of refractive indexes and extinction coefficient dependence are presented below (Fig. 9).

The roughness of the layers, in the case of ellipsometry, applies to the ITO / PEDOT system: PSS/ternary blend/Al cell morphology. The ellipsometric model of the sample does not calculate the parameters of the surface but an effective roughness layer is added to the model. The smoothness of the cell is undoubtedly affected by the PEDOT: PSS layer which when used, apart from supporting the charge transport, is a smoothing ITO surface. The roughness for ITO/PEDOT: PSS/PCBM: P3HT/Al was obtained and it was $20 \mathrm{~nm}$. The roughness for subsequent ternary bulk heterojunctions, with MPTM-IPQ1, was $16.0 \mathrm{~nm}$ for an admixture of $5 \%$; $7.6 \mathrm{~nm}$ for $10 \%$ and $4.4 \mathrm{~nm}$ for $15 \%$. Mixtures with MPTM-IPQ2 have a roughness of $20.0 \mathrm{~nm}, 19.0 \mathrm{~nm}, 11.6 \mathrm{~nm}$ respectively, and for the mixture of MPTM-IPQ2: P3HT: PCBM, $3.7 \mathrm{~nm}$, $3.4 \mathrm{~nm}$ and $2.9 \mathrm{~nm}$, respectively. The ellipsometric study showed a decrease of the roughness of the active layers with an increase in the MPTM-IPQ concentration-this result is consistent with Cha et al. [35] In addition, the demonstrated relationship is consistent with the increase in $\mathrm{V}_{\mathrm{oc}}$ as shown in the previous paragraph by Hörmann et al. [36].

The atomic force microscope research was conducted as the second part of the surface study. The measurements were carried out on a Bruker microscope, MultiMode VIII in the TappingMode mode, using silicon blades subsidized with antimony, with a nominal diameter of $8 \mathrm{~nm}$, a constant lever force of $40 \mathrm{~N} / \mathrm{m}$ and a resonance frequency of $300 \mathrm{kHz}$. The image sequence is shown in Fig. 10.

Based on the images; self-organization at the polymer/fullerene interface can be observed. The surface
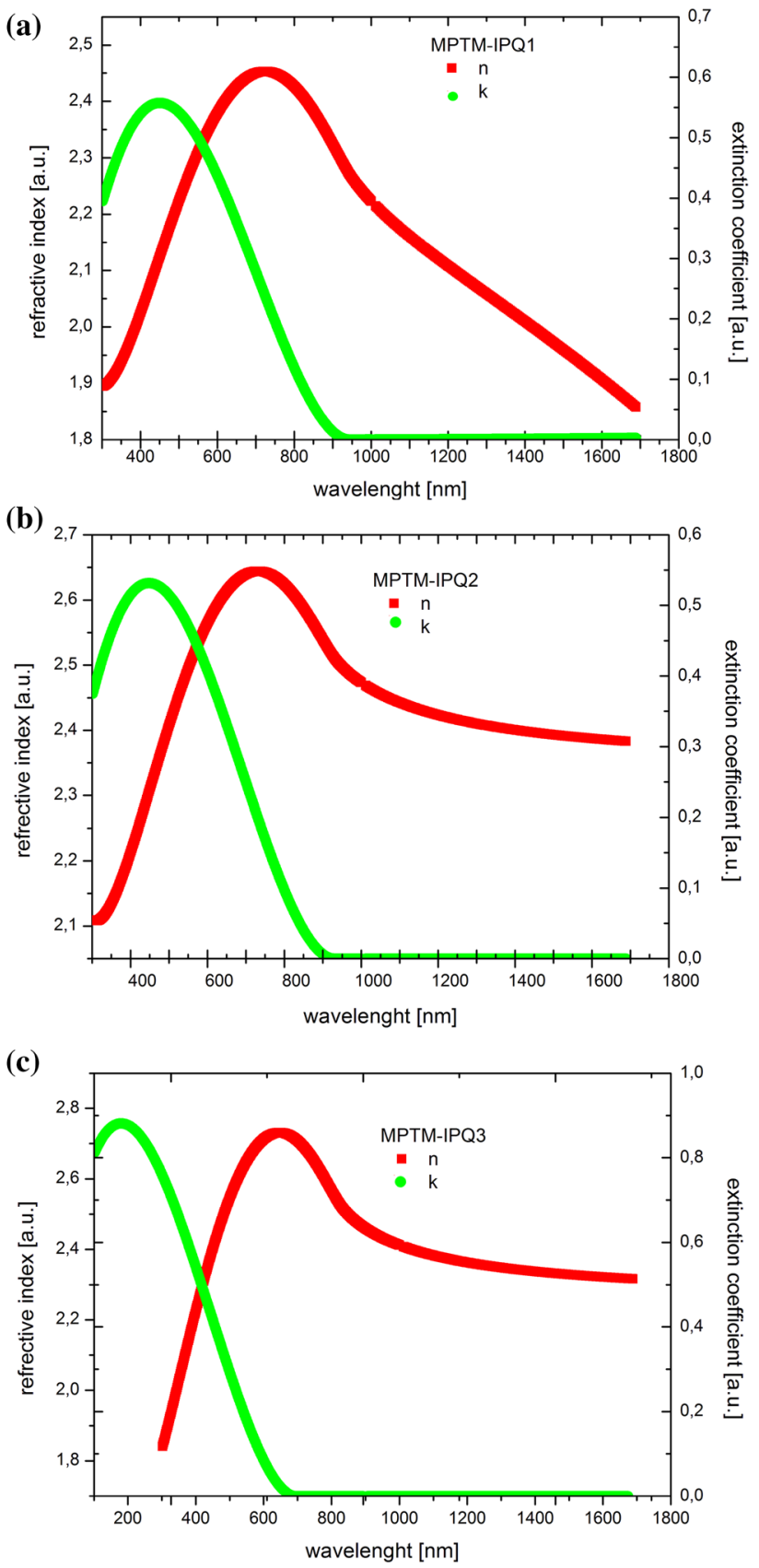

Fig. 9 The refractive indexes and extinction coefficient the dispersion dependence for a MPTM-IPQ1 b MPTM-IPQ2 c MPTM-IPQ3

parameters are collected in Table 2. $\mathrm{Ra}$ is referred to as the arithmetic mean roughness and $\mathrm{Rq}$ as root mean squared. It should be noted that the parameters of individual layers do not exceed $1 \mathrm{~nm}$. 
Fig. 10 AFM images MPTMIPQ1 + P3HT : PCBM mixtures
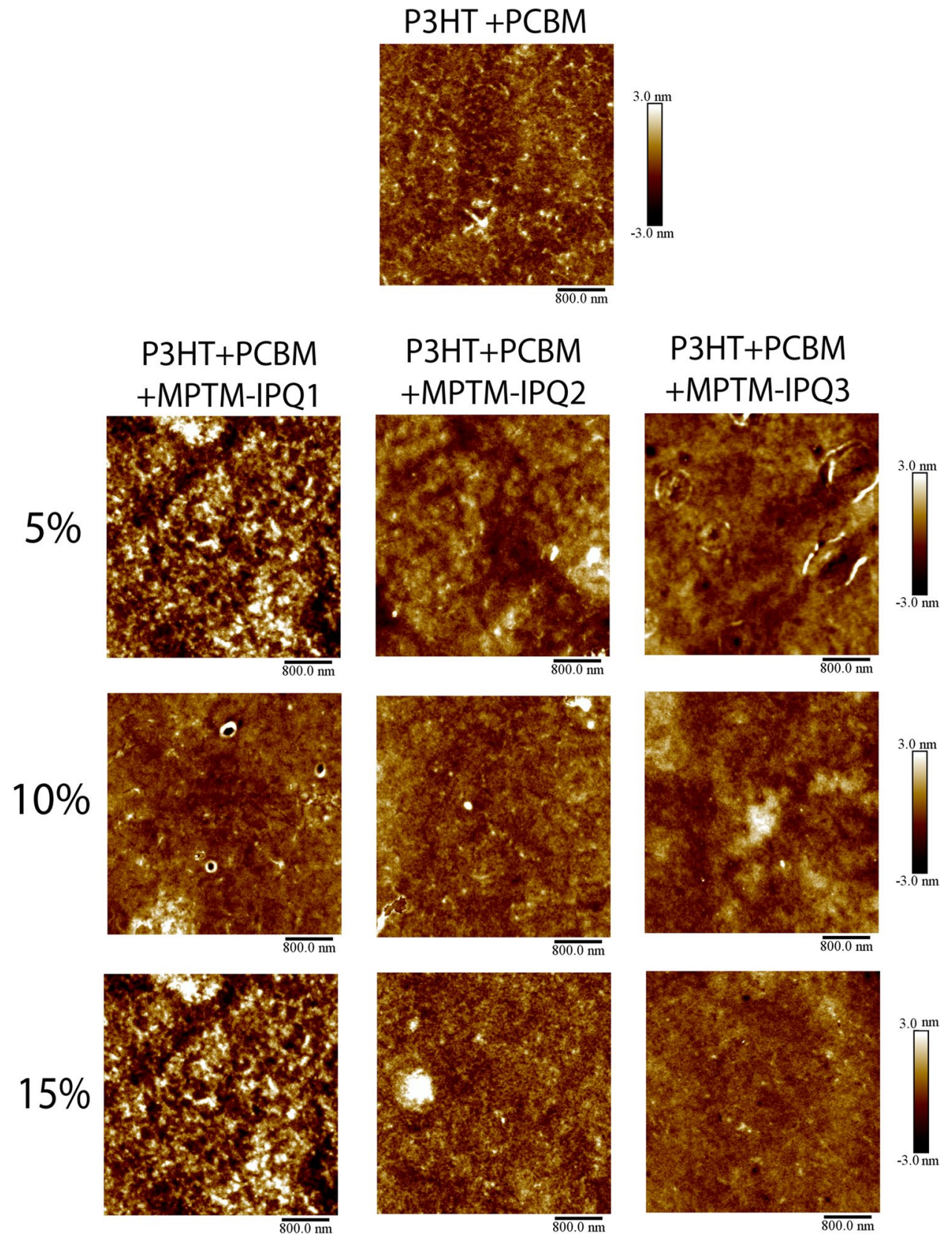

Table 2 AFM parameters

\begin{tabular}{|c|c|c|c|c|c|c|}
\hline \multirow[t]{3}{*}{ Additives } & \multicolumn{6}{|c|}{ AFM parameters } \\
\hline & \multicolumn{2}{|l|}{ MPTM-IPQ1 } & \multicolumn{2}{|l|}{ MPTM-IPQ2 } & \multicolumn{2}{|l|}{ MPTM-IPQ3 } \\
\hline & $\mathrm{Ra}[\mathrm{nm}]$ & $\mathrm{Rq}[\mathrm{nm}]$ & $\mathrm{Ra}[\mathrm{nm}]$ & $\mathrm{Rq}[\mathrm{nm}]$ & $\mathrm{Ra}[\mathrm{nm}]$ & $\mathrm{Rq}[\mathrm{nm}]$ \\
\hline P3HT: РCBM 0\% & $0.503 \pm 0.027$ & $0.663 \pm 0.042$ & $0.503 \pm 0.027$ & $0.663 \pm 0.042$ & $0.503 \pm 0.027$ & $0.663 \pm 0.042$ \\
\hline MPTM-IPQ1 + P3HT: PCBM 5\% & $1.03 \pm 0.20$ & $1.30 \pm 0.24$ & $0.59 \pm 0.12$ & $0.79 \pm 0.16$ & $0.492 \pm 0.015$ & $0.676 \pm 0.017$ \\
\hline MPTM-IPQ2 + P3HT: PCBM 10\% & $0.64 \pm 0.36$ & $0.98 \pm 0.48$ & $0.477 \pm 0.024$ & $0.630 \pm 0.005$ & $0.452 \pm 0.044$ & $0.577 \pm 0.063$ \\
\hline MPTM-IPQ3 + P3HT: PCBM 15\% & $0.750 \pm 0.055$ & $0.957 \pm 0.067$ & $0.508 \pm 0.058$ & $0.71 \pm 0.14$ & $0.368 \pm 0.034$ & $0.494 \pm 0.055$ \\
\hline
\end{tabular}




\section{Summary}

The behavior of doped methoxyphenyl indenopyrazoloquinoline derivatives is consistent with the results obtained for triazoloquinoxaline [37]. The most efficient weight proportion for the solar cell active layer with methoxyphenyl indenopyrazoloquinoline derivatives has been calculated and investigated. Due to the relatively narrow window of absorption of organic materials, the search for new solutions is particularly important. Open current voltage improvement and roughness of the layer reduction was observed. In the authors' opinion, previous research [38] mixing methoxyphenyl indenopyrazoloquinoline derivatives, P3HT and fullerene derivatives in blend film, improves nanomorphology as smaller domain sizes are observed. The active layer mixture can be considered as a guest (P3HT and PCBM)/ host (MPTM-IPQ) system.

Open Access This article is distributed under the terms of the Creative Commons Attribution 4.0 International License (http://creativeco mmons.org/licenses/by/4.0/), which permits unrestricted use, distribution, and reproduction in any medium, provided you give appropriate credit to the original author(s) and the source, provide a link to the Creative Commons license, and indicate if changes were made.

\section{References}

1. S. Yadav, K. Chattopadhyay, C.V. Singh, Solar grade silicon production: a review of kinetic, thermodynamic and fluid dynamics based continuum scale modeling. Renew. Sustain. Energy Rev. 78, 1288-1314 (2017). https://doi.org/10.1016/j.rser.2017.05.019

2. E. Płaczek-Popko, Top PV market solar cells 2016. OptoElectron. Rev 25, 55-64 (2017). https://doi.org/10.1016/j.opelr e.2017.03.002

3. S. Ranjan, S. Balaji, R.A. Panella, B.E. Ydstie, Silicon solar cell production. Comput. Chem. Eng. 35, 1439-1453 (2011). https:// doi.org/10.1016/j.compchemeng.2011.04.017

4. A.A. Ojo, I.O. Olusola, I.M. Dharmadasa, Effect of the inclusion of galium in normal cadmium chloride treatment on electrical properties OF CdS/CdTe solar cell. Mater. Chem. Phys. 196, 229 236 (2017). https://doi.org/10.1016/j.matchemphys.2017.04.053

5. C. Heisler, C.S. Schnohr, M. Hädrich, M. Oertel, C. Kraft, U. Reislöhner, H. Metzner, W. Wesch, Transparent CdTe solar cells with a ZnO:Al back contact. Thin Solid Films. 548, 627-631 (2013). https://doi.org/10.1016/j.tsf.2013.09.087

6. S. Sharma, B. Siwach, S.K. Ghoshal, D. Mohan, Dye sensitized solar cells: from genesis to recent drifts. Renew. Sustain. Energy Rev. 70, 529-537 (2017). https://doi.org/10.1016/j. rser.2016.11.136

7. P.P. Kumavat, P. Sonar, D.S. Dalal, An overview on basics of organic and dye sensitized solar cells, their mechanism and recent improvements. Renew. Sustain. Energy Rev. 78, 1262-1287 (2017). https://doi.org/10.1016/j.rser.2017.05.011

8. B. Kippelen, J.-L. Brédas, Organic photovoltaics. Energy Environ. Sci. 2, 251 (2009). https://doi.org/10.1039/b812502n

9. S. Antohe, S. Iftimie, L. Hrostea, V.A. Antohe, M. Girtan, A critical review of photovoltaic cells based on organic monomeric and polymeric thin film heterojunctions. Thin Solid Films. 642, 219-231 (2017). https://doi.org/10.1016/J.TSF.2017.09.041

10. H. Spanggaard, F.C. Krebs, A brief history of the development of organic and polymeric photovoltaics. Sol. Energy Mater. Sol. Cells. 83, 125-146 (2004). https://doi.org/10.1016/j.solma t.2004.02.021

11. G. Hodes, Perovskite-based solar cells. Science 342, 317-318 (2013). https://doi.org/10.1126/science. 1245473

12. T. Ameri, P. Khoram, J. Min, C.J. Brabec, Organic ternary solar cells: a review. Adv. Mater. 25, 4245-4266 (2013). https://doi. org/10.1002/adma.201300623

13. M.C. Chen, S. Kar, D.J. Liaw, W.H. Chen, Y.C. Huang, Y. Tai, Small organic additive to improve the charge separation in an inverted bulk heterojunction organic photovoltaic. Org. Electron. Phys. Mater. Appl. 13, 2702-2708 (2012). https://doi. org/10.1016/j.orgel.2012.07.033

14. Q. Fan, M. Li, P. Yang, Y. Liu, M. Xiao, X. Wang, H. Tan, Y. Wang, R. Yang, W. Zhu, Acceptor-donor-acceptor small molecules containing benzo[1,2-b:4,5-b']dithiophene and rhodanine units for solution processed organic solar cells. Dye Pigment. 116, 13-19 (2015). https://doi.org/10.1016/J.DYEPIG.2015.01.006

15. M. Zhang, F. Zhang, Q. An, Q. Sun, J. Wang, L. Li, W. Wang, J. Zhang, High efficient ternary polymer solar cells based on absorption complementary materials as electron donor. Sol. Energy Mater. Sol. Cells. 141, 154-161 (2015). https://doi.org/10.1016/j. solmat.2015.05.037

16. S. Banu, S.J. Ahn, S.K. Ahn, K. Yoon, A. Cho, Fabrication and characterization of cost-efficient $\mathrm{CuSbS}_{2}$ thin film solar cells using hybrid inks. Sol. Energy Mater. Sol. Cells. 151, 14-23 (2016). https://doi.org/10.1016/j.solmat.2016.02.013

17. M.L. Keshtov, A.R. Khokhlov, S.A. Kuklin, S.A. Osipov, N.A. Radychev, M.I. Buzin, G.D. Sharma, Benzothiadiazolepyrrolo[3,4-b]dithieno[2,3-f:3',2'-h]quinoxalindione-based random terpolymer incorporating strong and weak electron accepting $[1,2,5]$ thiadiazolo $[3,4 \mathrm{~g}]$ quinoxalinefor polymer solar cells. Org. Electron. 41, 1-8 (2017). https://doi.org/10.1016/j.orgel .2016 .11 .034

18. H. Wang, Y. Zheng, L. Zhang, J. Yu, Effect of two-step annealing on the performance of ternary polymer solar cells based on P3HT:PC71BM:SQ, Sol. Energy Mater. Sol. Cells. 128, 215-220 (2014). https://doi.org/10.1016/j.solmat.2014.05.026

19. Y.S. Choi, W.H. Jo, A strategy to enhance both Voc and Jsc of A-D-A type small molecules based on diketopyrrolopyrrole for high efficient organic solar cells. Org. Electron. Phys. Mater. Appl. 14, 1621-1628 (2013). https://doi.org/10.1016/j.orgel .2013.03.031

20. J. Sanetra, P. Armatys, R. Chrzaszcz, J. Pielichowski, P. Barta, S. Niziol, B. Saliraoui, Synthesis and luminescent properties of br-substituted poiy(n-vinylcarbazoles). Synth. Met. 101, 82-83 (1999). https://doi.org/10.1016/S0379-6779(98)01191-6

21. I. Fuks, B. Derkowska, B. Sahraoui, S. Niziol, J. Sanetra, D. Bogdal, J. Pielichowski, Third-order nonlinear optical susceptibility of polymers based on carbazole derivatives. J. Opt. Soc. Am. B. 19, 89 (2002). https://doi.org/10.1364/JOSAB.19.000089

22. A. Danel, Ł Chacaga, T. Uchacz, M. Pokladko-Kowar, E. Gondek, P. Karasiński, B. Sahraoui, Solution processable double layer organic light emitting diodes (OLEDs) based on 6-N,N -arylsubstituted-1 H-pyrazolo[3,4- b]quinolines. Adv. Device Mater. 1, 17-22 (2015). https://doi.org/10.1179/2055031614Y.0000000004

23. E. Gondek, I.V. Kityk, A. Danel, A. Wisla, M. Pokladko, J. Sanetra, B. Sahraoui, Electroluminescence of several pyrazoloquinoline and quinoksaline derivatives. Mater. Lett. 60, 3301-3306 (2006). https://doi.org/10.1016/J.MATLET.2006.03.051

24. M. Stępień, E. Gońka, M. Żyła, N. Spruta, Heterocyclic nanographenes and other polycyclic heteroaromatic compounds: synthetic 
routes, properties and applications. Chem. Rev. 117(4), 34793716 (2017). https://doi.org/10.1021/acs.chemrev6b00076

25. S. Ponnala, W.W. Harding, A route to azafluoranthene natural products through direct arylation. Eur. J. Org. Chem. 2013, 11071115 (2013). https://doi.org/10.1002/ejoc.201201190

26. A.V. Kityk, E. Gondek, M. Pokladko-kowar, K.S. Danel, M. Matusiewicz, W. Kuz, Methoxyphenyl indenopyrazoloquinoline derivatives as green fluorescent emitters for polymer based electroluminescent devices. Opt. Mater. (Amst) 34, 317-321 (2011). https://doi.org/10.1016/j.optmat.2011.08.013

27. M. Koppe, H.-J. Egelhaaf, G. Dennler, M.C. Scharber, C.J. Brabec, P. Schilinsky, C.N. Hoth, Near IR sensitization of organic bulk heterojunction solar cells: towards optimization of the spectral response of organic solar cells. Adv. Funct. Mater. 20, 338-346 (2010). https://doi.org/10.1002/adfm.200901473

28. N. Felekidis, E. Wang, M. Kemerink, Open circuit voltage and efficiency in ternary organic photovoltaic blends. Energy Environ. Sci. 9, 257-266 (2016). https://doi.org/10.1039/C5EE03095A

29. J. Singh, M. Narayan, D. Ompong, F. Zhu, Dissociation of charge transfer excitons at the donor-acceptor interface in bulk heterojunction organic solar cells. J. Mater. Sci. Mater. Electron. 28, 7095-7099 (2017). https://doi.org/10.1007/s10854-017-6443-3

30. C. Wang, X. Xu, W. Zhang, S. Ben Dkhil, X. Meng, X. Liu, O. Margeat, A. Yartsev, W. Ma, J. Ackermann, E. Wang, M. Fahlman, Ternary organic solar cells with enhanced open circuit voltage. Nano Energy 37, 24-31 (2017). https://doi.org/10.1016/j.nanoe n.2017.04.060

31. D.E. Aspnes, Spectroscopic ellipsometry-past, present, and future. Thin Solid Films. 571, 334-344 (2014). https://doi. org/10.1016/J.TSF.2014.03.056

32. M. Campoy-Quiles, T. Ferenczi, T. Agostinelli, P.G. Etchegoin, Y. Kim, T.D. Anthopoulos, P.N. Stavrinou, D.D.C. Bradley, J.
Nelson, Morphology evolution via self-organization and lateral and vertical diffusion in polymer: fullerene solar cell blends. Nat. Mater. 7, 158-164 (2008). https://doi.org/10.1038/nmat2102

33. A.S. Ferlauto, G.M. Ferreira, J.M. Pearce, C.R. Wronski, R.W. Collins, X. Deng, G. Ganguly, Analytical model for the optical functions of amorphous semiconductors from the near-infrared to ultraviolet: applications in thin film photovoltaics. J. Appl. Phys. 92, 2424-2436 (2002). https://doi.org/10.1063/1.1497462

34. G.E. Jellison, F.A. Modine, Parameterization of the optical functions of amorphous materials in the interband region. Appl. Phys. Lett. 69, 371-373 (1996). https://doi.org/10.1063/1.118064

35. H. Cha, C.E. Park, S.-K. Kwon, T.K. An, Ternary blends to achieve well-developed nanoscale morphology in organic bulk heterojunction solar cells. Org. Electron. 45, 263-272 (2017). https://doi.org/10.1016/j.orgel.2017.03.028

36. U. Hörmann, C. Lorch, A. Hinderhofer, A. Gerlach, M. Gruber, J. Kraus, B. Sykora, S. Grob, T. Linderl, A. Wilke, A. Opitz, R. Hansson, A.S. Anselmo, Y. Ozawa, Y. Nakayama, H. Ishii, N. Koch, E. Moons, F. Schreiber, W. Brütting, Voc from a morphology point of view: the influence of molecular orientation on the open circuit voltage of organic planar heterojunction solar cells. J. Phys. Chem. C 118, 26462-26470 (2014). https://doi.org/10.1021/ jp506180k

37. Q. Sun, F. Zhang, J. Hai, J. Yu, H. Huang, F. Teng, W. Tang, Doping a D-A structural polymer based on benzodithiophene and triazoloquinoxaline for efficiency improvement of ternary solar cells. Electron. Mater. Lett. 11, 236-240 (2015). https://doi. org/10.1007/s13391-014-4326-9

38. N. Marinova, S. Valero, J.L. Delgado, Organic and perovskite solar cells: working principles, materials and interfaces. J. Colloid Interface Sci. 488, 373-389 (2017). https://doi.org/10.1016/j. jcis.2016.11.021 